\title{
Regeneration Process Improvement of Demineralization Unit in LNG Plant Bontang
}

\author{
Okky W. Lukman
}

\begin{abstract}
PT Badak NGL is a world class company located in Bontang. The company is capable to produce liquefied natural gas (LNG) and liquefied petroleum gas (LPG) with the maximum capacity of 22.5 MTPA and 1 MTPA, respectively. In order to support the gas liquefaction process, PT Badak NGL operates large scale of utility plants as well.

One of the recent problems in the utility systems is related to the boiler feed water's treatment process. PT Badak NGL uses the ion exchange for demineralization process to treat and purify the ground water. Demineralization Unit in PT Badak NGL had very low performance due to the conductivity and silica premature breakthrough. Incomplete regeneration process in Cation and Anion Exchanger vessel and the worse quality of resin were suspected as the causes of this problem. As a consequence, the regeneration process should be done more often and then caused higher chemical cost.

An elution study was performed to analyze the effectiveness of ion exchange regeneration process. As a solution, an improved acid and caustic displacement sequence was applied to achieve the optimum regeneration process. The duration of acid and caustic displacement was prolonged to completely relieve the residual regenerant left in the vessel. The next improvement was also conducted by adding the extra backwash period to rinse all the remaining acid in the Cation Exchanger. This new procedure of regeneration process has been proven to achieve the proper quality of boiler feed water and reduce $23 \%$ of total chemical cost in demineralization process.
\end{abstract}

\section{Keywords - demineralization, ion exchange, regeneration}

\section{INTRODUCTION}

As a world class company, PT Badak NGL which is located in Bontang, East Kalimantan, Indonesia, is capable to produce liquefied natural gas (LNG) and liquefied petroleum gas (LPG) with the maximum capacity of 22.5 MTPA and 1 MTPA, respectively. In order to support the gas liquefaction process, PT Badak NGL operates large scale of utility plants as well such for water treatment, steam and power generation, nitrogen plant, cooling water plant, etc. PT Badak NGL also produces high purity of steam to be a driven for many turbines, pumps, etc. In order to fulfil the requirement of the high steam purity, the water treatment plant has an important role, where the raw water is treated to be utilized as a boiler feed water in the boiler. The steps of water treatment process are aeration, filtration, and demineralization. The demineralization process takes a main function for removing all salts and minerals contained in the water by implementing the ion exchange system. There are two vessels in Demineralization Unit i.e. Cation Exchanger and Anion Exchanger which are filled by resin. As a product of

Okky W. Lukman, PT Badak NGL, Bontang-Indonesia demineralization unit, a high purity of boiler feed water is ready to be generated as steam.

Demineralization process is mainly performed to remove all mineral and salts contained in the filtered water after aeration and filtration process. There are two ion exchange vessels which each of it is utilized by passing the water through the ion exchange resin. By using the Cation and Anion Exchanger, all the ions are exchanged with the cation and anion resin to be demineralized water. The simplified scheme of Demineralization Unit can be seen in Figure 1 as follow:

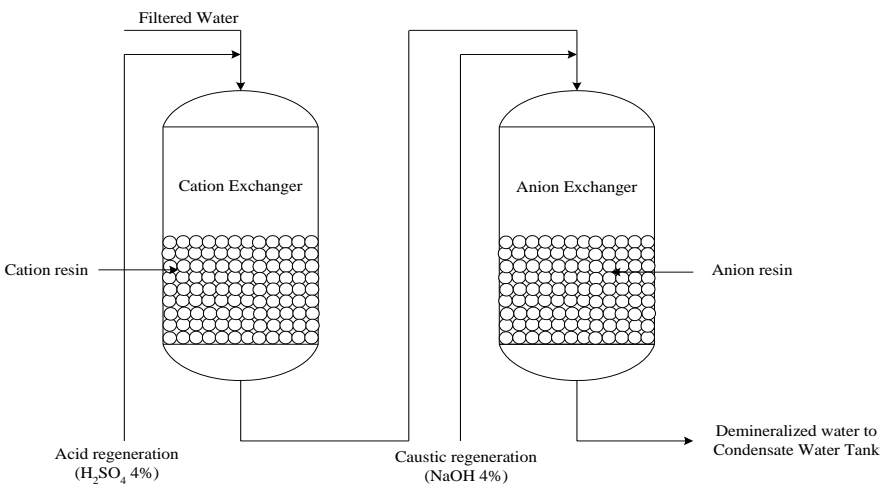

Fig.1. Ion Exchange System in Demineralization Unit

The cation and anion exchange reactions can be seen as follow:

Fig.2. Cation and Anion Exchange Reactions

The sequential steps of regeneration in Demineralization
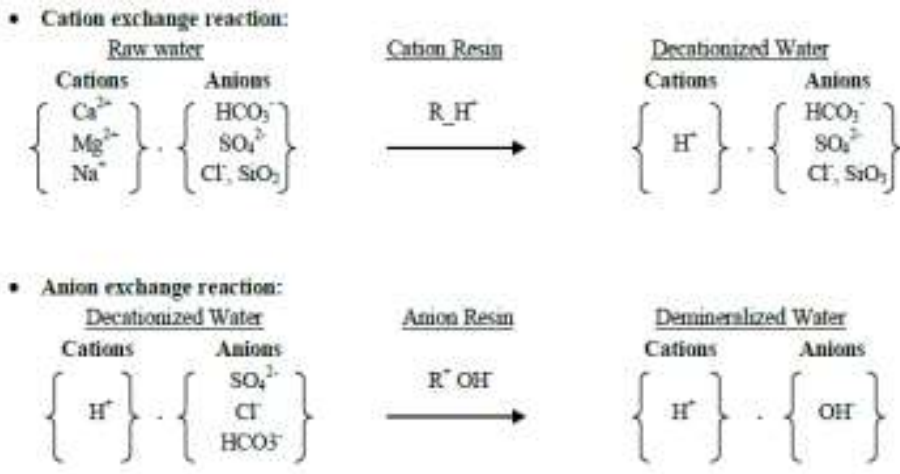

Unit are backwash, chemical injection, displacement, and rinse. Backwash step is conducted to raise up the dirt that are accumulated in the bottom of the vessel. Backwash process can also relieve the broken resins that are floating in the surface of the water. Chemical injection is done to regenerate the resin 
with the specific regenerant; acid for the cation resin and caustic soda for the anion resin. The next step of regeneration process is displacement. The function of displacement process is to fully accomplish the regeneration (chemical injection step) while the rinse process is conducted to rinse the bed and set up the condition of the bed to be put in service mode. Before being put in service mode to supply demineralized water to Condensate Water Tank, the service rinse mode is performed to ensure the specification of water's conductivity till meets the requirement of maximum $5 \mu \mathrm{mhos} / \mathrm{cm}$.

One of the repetitive problems in Demineralization Unit was about the conductivity and silica premature breakthrough. Due to the conductivity and silica premature breakthrough, Demineralization Unit could not reach the normal setting counter. PT Badak NGL has two units demineralization to support the boiler feed water requirement for 4 trains running. The demineralization unit is called Demineralization $\mathrm{E}$ and $\mathrm{F}$.

Another problem was about the long time of service rinse period in each regeneration process. Refer to the regeneration steps of Demineralization Unit, there was a service rinse period after finishing the fast rinse step in both Cation and Anion Exchangers. The service rinse step is implemented to recycle the outlet water into Filtered Water Tank until the conductivity of the water meets the specification of maximum limit of 5 $\mu \mathrm{mhos} / \mathrm{cm}$. However, the service rinse step normally took very long time period before being online to the system. This condition did't only led the longer of time but also decreasing the service counter of Demineralization Unit itself. By those considerations, the improvement was conducted to evaluate the performance of Demineralization Unit.

\section{CHANGE FOR MODIFICATION}

The improvement should be done to get the better performance of Demineralization Unit. The conductivity and silica premature breakthrough caused the faster period of regeneration process. By its low service counter, the chemical consumption due to regeneration process was higher. On the other hand, the service rinse step still consumed lots of time before being online to the system.

\section{TeChNiCAl Evaluation}

In the case of Demineralization problem, the premature breakthrough was happened both for conductivity and silica content in the demineralized water. The high conductivity content was normally happened because the ion exchange process is not properly done in the Cation Exchanger whereas the high silica content is commonly caused by the low performance of Anion Exchanger. The first suspect was the incomplete regeneration process in both Cation and Anion Exchangers so that the conductivity and silica was considered still high.

The performance test of regeneration process was then conducted for both Cation and Anion Exchanger. The objective of this performance test was to ensure how well the regeneration process is conducted. Total consumption of regenerant for both Cation and Anion Exchangers should also be considered. Nowadays, the acid and caustic used are 128 $\mathrm{kg} / \mathrm{m}^{3}$ resin and $100 \mathrm{~kg} / \mathrm{m}^{3}$ resin (equivalent with $65 \mathrm{~mm}$ acid and $285 \mathrm{~mm}$ caustic in each chemical tank). Another parameter of regeneration process is displacement step which can accomplish the regeneration process in injection step. The duration of acid displacement and caustic displacement were 30 minutes and 1 hour respectively. In order to know the performance of regeneration process, the elution study was used to evaluate and determine how effective the resin is being regenerated by using those chemicals.

The elution study was especially done in order to solve this earlier breakthrough of Demineralization E by plotting the total ions contained in the demineralized water and the regenerant concentrations to qualitatively evaluate the regeneration process. Total ions in the water during regeneration process are shown by the conductivity analysis which was periodically monitored. A good regenerant curve should have moderate rise in concentration during injection step then ultimately level off after injection period finished and directly steep decrease in concentration during displacement or rinse step.

Elution study of Demineralization E was conducted in both Cation and Anion Exchangers. The figure of acid and caustic injection to Cation Exchanger and Anion Exchanger can be seen in Figure 3 and 4 as follows:

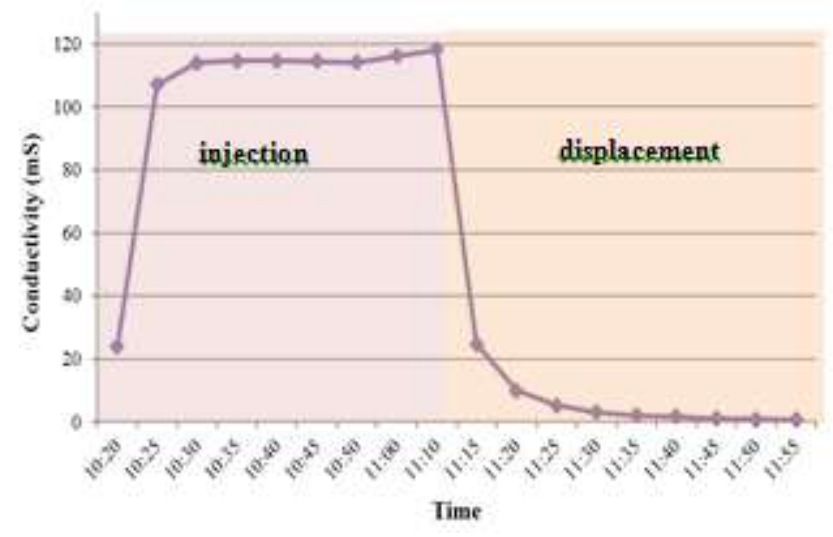

Fig.3. Regenerant Curve for Cation Regeneration

Based on Figure 3 above, total acid injected to Cation Exchanger was considered good enough. It was shown by the flat figure at the end of injection step which occurred as long as 50 minutes. But for the acid displacement step which was normally performed for 30 minutes, it was considered not enough. The total ions contained in the decationized water still decreased till more than 45 minutes. It can be conclude that the improvement should be done especially for acid displacement step in the Cation Exchanger. All regenerants were considered wasted after more than 45 minutes of acid displacement. In order to optimize the regenerants wasted from the Cation Exchanger, the acid displacement step was then extended from 30 minutes to 1 hour.

Besides the regeneration step in Cation Exchanger, the duration of chemical injection and displacement were also evaluated in the Anion Exchanger. 


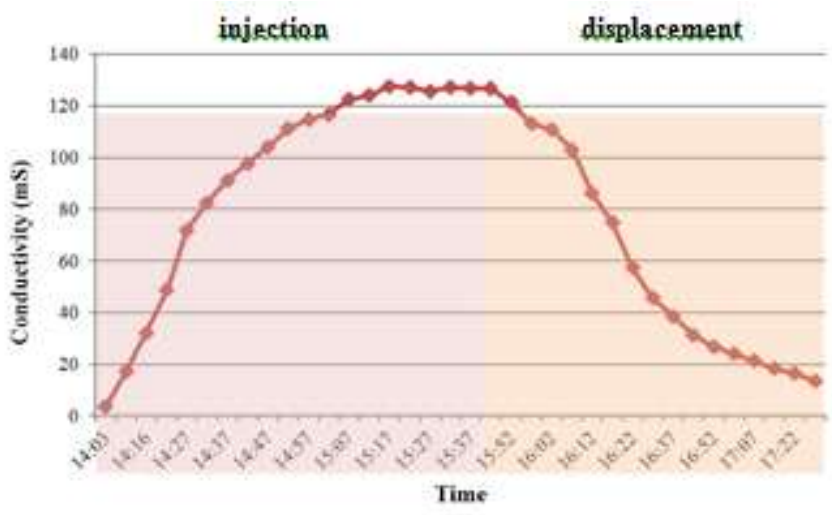

Fig.4. Regenerant Curve for Anion Regeneration

Based on Figure 4 above, the total caustic injected to the Anion Exchanger was considered good. For caustic injections, the total chemical injected to the vessel was sufficient to absorb all the ions in the vessel (shown by the flat figure at the end of injection step). But for the displacement step, it needed an improvement to prolong the duration of caustic displacement step. In the Anion Exchanger, the caustic displacement step that normally occurred for 1 hour was not enough to relieve the residual regenerant left in the vessel. Refer to the result of this performance test, the duration of caustic displacement step should be extended to 2 hours.

After the completion of Demineralization's performance test, the next improvement was to ensure the condition of the bed in both Cation and Anion Exchanger. From the inspection activities, the findings were as follows:

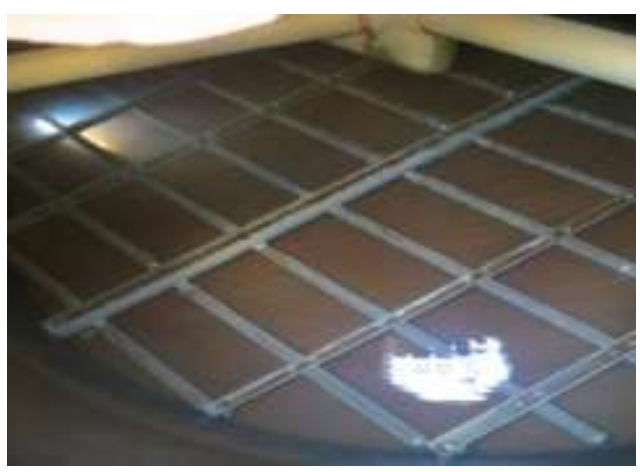

Fig.5. Bed's Condition of Cation Exchanger

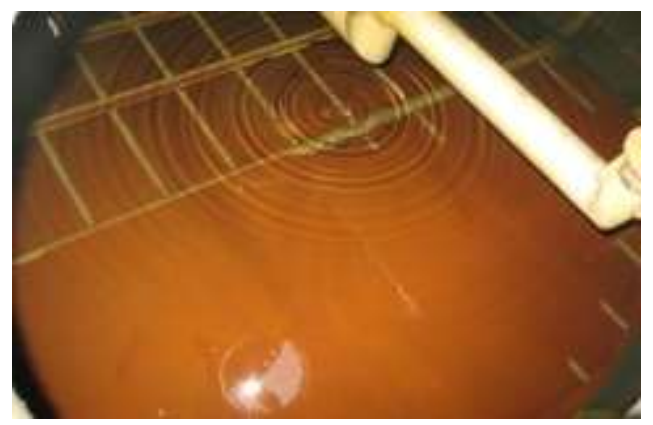

Fig.6. Bed's Condition of Anion Exchanger
- The condition of Cation Exchanger's bed was considered good enough. But there was an indication of resin's mal-distribution in the Anion Exchanger that was possible caused by the broken or damaged lateral distributors. The internal inspection was then conducted especially in Anion Exchanger due to that finding.

13 of 20 lateral distributors at the middle of the Anion Exchanger for injection were found torn.

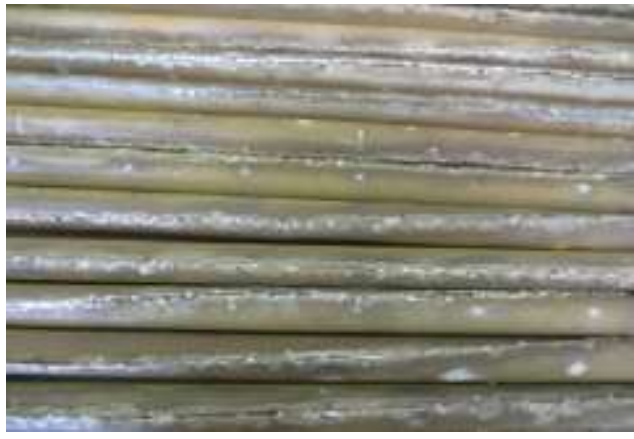

Fig.7. Lateral Distributors Condition

- No defect or damage was found on the bottom lateral distributors (Johnson strainer).

On the other hand, the performance of demineralization is determined by the proper control system in the vessel. During the performance test of Demineralization Unit, it was found that lots of instrumentation equipments which especially support the Demineralization Unit were found in bad condition. Some of them did not indicate the actual conditions, some of them had different measurement with the indication in DCS, and some of them needed to be recalibrated. At the same time, the bypass control valve from the inlet feed of Cation Exchanger to the bottom line of the product (demineralized water) was found passing. This problem was considered contributed to the premature breakthrough of conductivity content due to filtered water directly flowed to the Anion Exchanger without passing through Cation Exchanger so that the cation exchange process did not take place completely, including its regeneration process.

On the other hand, the anion resin analysis was then conducted by the supporting laboratory facilities from GE Water \& Process Technologies. It was revealed that the total exchange capacity of anion resin has decreased to $77 \%$ of typical new resin (from maximum $1.3 \mathrm{mEq} / \mathrm{mL}$ to $1 \mathrm{mEq} / \mathrm{mL}$ ) which possibly caused by the resin degradation or resin fouling. The physical properties of anion resin were still relatively good based on the total broken beads and cracked beads which were still below than the maximum requirements.

Refer to the resin analysis result, the problem could be solved by improving the method of regeneration process to get the optimum resin condition in the vessel. The modification of the sequence of some regeneration steps in Demineralization Unit had been conducted by prolonging the acid displacement period's in Cation Exchanger to 60 minutes from the initial design of 22 minutes whereas the caustic displacement's period in Anion Exchanger had also been prolonged to 120 minutes 
from design procedure of 45 minutes. Based on the operational condition, this improvement was considered not enough to get the best performance of Demineralization Unit. The problem of silica premature breakthrough occurred again in the mid of September 2015 so the Demineralization Unit couldn't achieve the normal setting counter again. The figure of Demineralization Unit's performance can be seen in Figure 8 as follow:

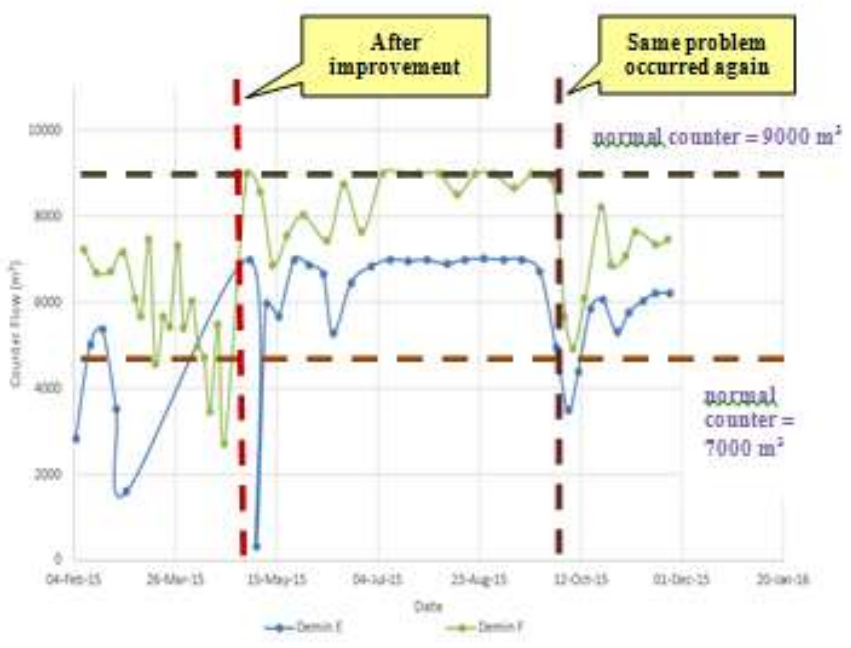

Fig.8. Trending of Demineralization Unit's Performance

Based on the performance trends of Demineralization E and F on Figure 8 above, both of Demineralization E and F couldn't constantly achieve the normal counter flow of 7000 and 9000 $\mathrm{m}^{3}$. Based on the plant observation, there was no any problem with the unit and the whole control valves installed in the Demineralization Unit. This condition was considered caused by the quality of the ion exchange resin itself. Due to resin aging, performance of Demineralization Unit is also changed. Inorganic and organic fouling still happen despite tight pre-treatment control is performed. This fouling causes chemical displacement more difficult than before. On the other side, another problem is about the service rinse step. Service rinse step after fast rinse still consumed a lot of time which also reduced the service counter of Demineralization Unit itself. The service rinse period takes 8-12 hours for each Demineralization Unit before putting it in service mode.

In order to compromise with present resin condition and performance of Demineralization Unit, the modification of regeneration process should be conducted. The proposed improvement is to reduce service rinse duration is by conducting extra backwash at Cation Exchanger in the step after fast rinse sequence. The plant observation of adding extra backwash step was started since December 2015. Based on actual plant test, the service counter of Demineralization Unit tends to be longer if the extra backwash is performed. The comparison of Demineralization E and F service counter's either by implementing the extra backwash step or not can be seen in Figure 9 as follow:

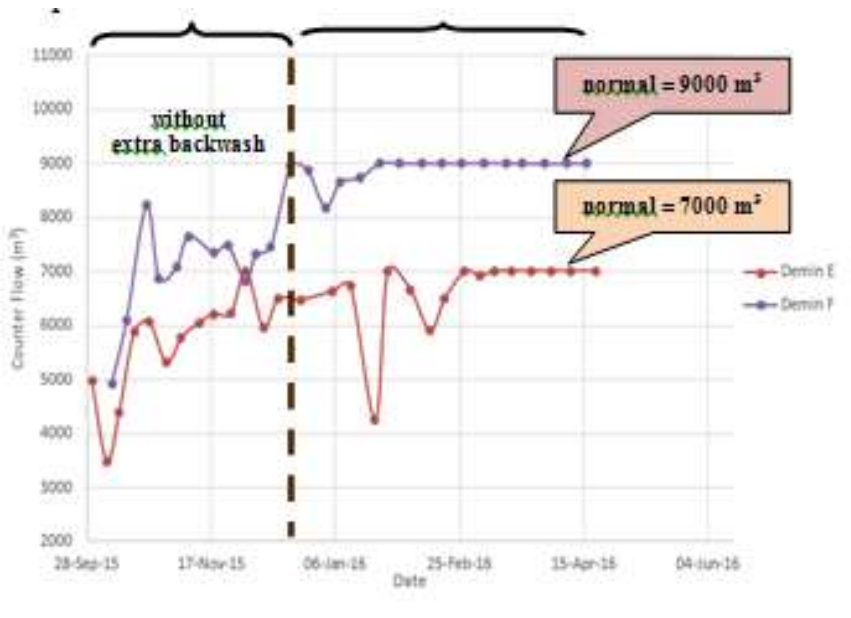

Fig.9. Trending of Demineralization's Counter Flow

Based on the plant observation which is also shown on Figure 9 above, the service counter of Demineralization Unit with the extra backwash step is evenly better and meets the normal setting counter of $7000 \mathrm{~m}^{3}$ and $9000 \mathrm{~m}^{3}$. Extra backwash is conducted after fast rinse step in Cation Exchanger Unit, with the flow rate of $90 \mathrm{~m}^{3} / \mathrm{hr}$ rate and 10 minutes time's duration. This additional sequence can practically reduce service rinse period which the water is recycled to Filtered Water Tank. Service rinse is performed until the electrolyte conductivity achieves the specification of maximum limit $5 \mu \mathrm{mhos} / \mathrm{cm}$. Before conducting the extra backwash step, it takes 8 - 12 hours for service rinse step, which means it has already used $720-1080 \mathrm{~m}^{3}$ of service counter in Demineralization Unit.

On other hand, by adding extra backwash before conducting service rinse was proved to reduce the duration service rinse from 8-12 hours to around 1-2 hours. In order to ensure the effect of extra backwash step in the overall regeneration process, the sampling of decationized water was taken to be deeply analyzed in the Laboratory. There were two types of sample that were analyzed; decationized water before extra backwash and decationized water after extra backwash. The supposed result of those samples can prove the effect of extra backwash step in the regeneration process. Several electrolyte parameters were analyzed which the result can be seen in Table 1 as follow: 
TABLE I: Laboratory ANALYSIS OF Demineralized Water DuRING BACKWASH PERIOD

\begin{tabular}{|c|c|c|c|c|c|c|c|c|}
\hline \multirow{3}{*}{$\underset{\text { ter }}{\text { Parame }}$} & \multicolumn{2}{|c|}{ Demin E } & \multicolumn{2}{|c|}{ Demin F } & \multicolumn{2}{|c|}{ Demin E } & \multicolumn{2}{|c|}{ Demin F } \\
\hline & \multicolumn{2}{|c|}{ 24-May-16 } & \multicolumn{2}{|c|}{ 15-Jun-16 } & \multicolumn{2}{|c|}{ 18-Jun-16 } & \multicolumn{2}{|c|}{ 6-Jul-16 } \\
\hline & B & $\mathbf{A}$ & B & $\mathbf{A}$ & B & $\mathbf{A}$ & B & $\mathbf{A}$ \\
\hline $\mathrm{pH}$ & 3.49 & 3.66 & 3.57 & 3.58 & 3.35 & 3.48 & 3.37 & 3.39 \\
\hline $\begin{array}{c}\text { Conduc } \\
\text { tivity } \\
(\mu \mathrm{mhos} / \\
\mathrm{cm})\end{array}$ & 255 & 148 & 131.8 & 121.6 & 177.6 & 124.1 & 168.1 & 155.6 \\
\hline $\begin{array}{c}\mathrm{Fe} \\
(\mathrm{ppm})\end{array}$ & 0.05 & 0.06 & $<0.05$ & $<0.05$ & $<0.05$ & $<0.05$ & 0.08 & 0.06 \\
\hline $\begin{array}{c}\mathrm{Na} \\
(\mathrm{ppm})\end{array}$ & 0.43 & 0.24 & 0.185 & 0.243 & 0.432 & 0.211 & 0.298 & 0.181 \\
\hline $\begin{array}{c}\mathrm{Mn} \\
(\mathrm{ppm})\end{array}$ & $\begin{array}{c}< \\
0.03\end{array}$ & $\begin{array}{c}< \\
0.03 \\
\end{array}$ & $<0.03$ & $<0.03$ & $<0.03$ & $<0.03$ & $<0.03$ & $<0.03$ \\
\hline $\begin{array}{c}\mathrm{Cu} \\
(\mathrm{ppm})\end{array}$ & $\begin{array}{c}< \\
0.02 \\
\end{array}$ & $\begin{array}{c}< \\
0.02 \\
\end{array}$ & $<0.02$ & $<0.02$ & $<0.02$ & $<0.02$ & $<0.02$ & $<0.02$ \\
\hline $\begin{array}{l}\mathrm{NO}_{3}^{-} \\
(\mathrm{ppm})\end{array}$ & 0.03 & 0.03 & 0.02 & 0.02 & 0.04 & 0.03 & 0.04 & 0.04 \\
\hline $\begin{array}{c}\mathrm{SO}_{4}{ }^{2-} \\
(\mathrm{ppm})\end{array}$ & 19 & 8 & 8 & 8 & 13 & 7 & 11 & 10 \\
\hline $\begin{array}{c}\mathrm{Mg} \\
(\mathrm{ppm})\end{array}$ & $\begin{array}{c}< \\
0.00 \\
3 \\
\end{array}$ & $\begin{array}{c}< \\
0.00 \\
3 \\
\end{array}$ & $\begin{array}{c}< \\
0.003\end{array}$ & $\begin{array}{c}< \\
0.003\end{array}$ & $\begin{array}{c}< \\
0.003\end{array}$ & $\begin{array}{c}< \\
0.003\end{array}$ & 0.004 & 0.004 \\
\hline $\begin{array}{c}\mathrm{Ca} \\
(\mathrm{ppm})\end{array}$ & 0.01 & 0.01 & $<0.01$ & $<0.01$ & 0.01 & $<0.01$ & 0.009 & 0.022 \\
\hline $\begin{array}{l}\mathrm{HCO}_{3}^{-} \\
(\mathrm{ppm})\end{array}$ & nil & nil & nil & nil & nil & nil & nil & nil \\
\hline $\begin{array}{c}\mathrm{Cl}^{-} \\
(\mathrm{ppm})\end{array}$ & 1.3 & 1.3 & 1.3 & 1.3 & 1.6 & 1.6 & 2.1 & 2.3 \\
\hline $\begin{array}{c}\mathrm{SiO}_{2} \\
(\mathrm{ppm})\end{array}$ & 16.9 & 16.9 & 12.76 & 12.76 & 12.2 & 13.7 & 14.82 & 14.82 \\
\hline
\end{tabular}

Note : $\mathrm{B}$ = before backwash step ; $\mathrm{A}=$ after backwash step

As provided in Table 1 above, most of the parameters analyzed show the similar result between two samples (decationized water before and after extra backwash), except the electrolyte conductivity and sulphate content with the extra backwash step which are lower than previous normal step of regeneration process, especially at Demineralization E. The electrolyte conductivity was seemed lower both in Demineralization E and F after conducting the extra backwash step. This result proves that extra backwash step in regeneration process is needed to reduce the electrolyte conductivity in the decationized water. Another parameter observed was the $\mathrm{SO}_{4}{ }^{2-}$ content. $\mathrm{SO}_{4}{ }^{2-}$ content of decationized water was also seemed significantly lower especially in Demineralization E. $\mathrm{SO}_{4}{ }^{2-}$ content in Demineralization $\mathrm{E}$ before extra backwash step was still high compared with the $\mathrm{SO}_{4}{ }^{2-}$ content of decationized water in Demineralization $\mathrm{F}$ (in average $16 \mathrm{ppm}$ vs $9.5 \mathrm{ppm}$ from two samples analysed). After conducting the extra backwash step, the $\mathrm{SO}_{4}{ }^{2-}$ content significantly dropped. Based on this condition, extra backwash step is needed to rinse all the acid remained in the decationized water. Refer to this result, the difference between $\mathrm{SO}_{4}{ }^{2-}$ content in the Demineralization $\mathrm{E}$ and $\mathrm{F}$ may be caused by the quality of the resin in the Demineralization E and F itself.

The suspect of this condition was probably caused by the worse condition of resin in Demineralization E. This improper quality of the resin can be caused by the resin aging. Based on the historical data, the resin in Demineralization Unit has never been replaced since the first time operation of Demineralization Unit. Resin aging is also contributed by the inorganic and organic fouling. In order to solve the problem,

extra treatment in regeneration process should be added. One of the possible improvements is to add the extra backwash step in the last step regeneration process in Cation Exchanger.

This extra backwash program which is put at the end of regeneration sequence is considered strongly fit out the rinse step by removing the remaining sulphuric acid which attached at lower resin bed. The simplified diagram of remaining sulphuric acid in resin bed can be seen at Figure 10 below:

(a)

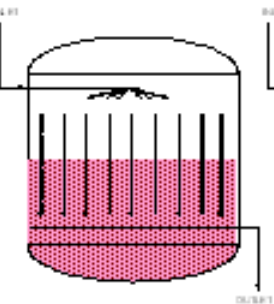

Fig.10. Bed Condition After Acid Injection (a); Displacement-Rinse (b); Extra Backwash (c)

During acid displacement and rinse, resin's bed becomes compacted. It is caused by pressure of downward flow. As a compact bed, the remaining chemicals attached at resin's surface will be harder to be stripped out. For new or less fouled resin, the remaining sulphuric acid can be easily removed throughout this downward flow, but for fouled resin, the removal process will be harder. With this improvement, by adding extra backwash step, it pushes the resin bed from bottom of the vessel to expand and strip out the remaining sulphate ion especially where attached at below of lateral distributor. By reducing sulphate content of outlet cation vessel, anion resin load will be reduced. Less anion exchange load tends longer anion exchanger service counter. Water treated quantity should be maximized in order to reduce regeneration frequency which means less chemical consumption and reduce waste water to environment.

Based on the observation, the improvement of regeneration process in Demineralization Unit is proven effective to solve the conductivity and silica premature breakthrough and reduce the rinse water dumped into environment. The performance of Demineralization Unit is better than before nowadays. With this improvement program of regeneration process improvement, PT Badak NGL can reduce as much as 74,880 $\mathrm{m}^{3}$ of water disposed to the environment per year. On the other hand, this improvement can also reduce the chemical cost of regeneration process as much as $23 \%$ of total chemical cost per year. This saving cost of may be not significantly impact the total cost of operating budget of PT Badak NGL, but in term of environmental issue, it will give a good point for the contribution of water conservation program.

\section{CONCLUSION}

Based on the improvement that was performed in Demineralization Unit by modifying the sequence of regeneration process especially for acid and caustic displacement and the additional extra backwash step which 
was then implemented, the Demineralization Unit has better performance nowadays. This improvement can also reduce the frequency of regeneration process and reduce the chemical cost as much as $23 \%$ of total chemical cost per year. In addition, the additional extra backwash step in regeneration process can reduce $74,880 \mathrm{~m}^{3}$ of demineralized water disposed to the environment per year.

\section{ACKNOWLEDGMENT}

This research was fully supported and granted by PT Badak NGL permission. I also thank my colleagues from Technical and Operation Department who provided insight, expertise, and greatly cooperation thorough the research.

\section{REFERENCES}

[1] J. Jacobsen, "Elution Studies" presented at the Water Chemistry Round AEP BRO, 2010.

[2] Perdana. F. A., "High Conductivity at Demin Unit F," Process \& SHE Engineering Troubleshooting Report, Dept. Technical., PT Badak NGL., Bontang, Indonesia, 2012.

[3] Purnawan. A. P., "Evaluation of Demin A-D Operation," Process \& SHE Engineering Memorandum, Dept. Technical., PT Badak NGL., Bontang, Indonesia, 2005.

[4] Setiawan. M. A., "Change in Demineralizer A/B/C (36V-2/4-A/B/C) Service Period (Counter)," Process \& SHE Engineering Memorandum, Dept. Technical., PT Badak NGL., Bontang, Indonesia, 2009.

[5] Setiawan. M. A., "Demineralizer 36V-2D Repair," Process \& SHE Engineering Memorandum, Dept. Technical., PT Badak NGL., Bontang, Indonesia, 2008.

[6] Setiawan. M. A., "Improvement of Lateral Distributor in Cation Exchanger Vessel (36V-2B/C)," Process \& SHE Engineering Memorandum, Dept. Technical., PT Badak NGL., Bontang, Indonesia, 2009.

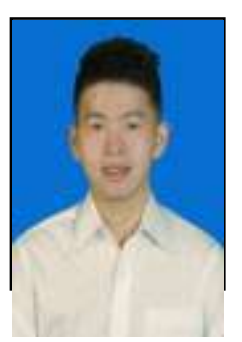

Okky W. Lukman was born in Bandung on October 11, 1990. He received the S.T. degree in chemical engineering from Bandung Institute of Technology (ITB), Bandung, Indonesia, in 2013.

From the end of 2013, he joined a world class enery company, PT Badak NGL Bontang, which produces liquefied natural gas (LNG) and liquefied petroleum gas (LPG). He is expert in utility system of LNG and LPG production such as for water treatment, steam and power generation, nitrogen plant, and cooling water plant. 